\title{
Políticas de Estado e organização político-pedagógica da escola: entre o instituído e o instituinte
}

Sueli Menezes Pereira*

\section{Resumo}

Tendo como foco o projeto pedagógico das escolas, o objetivo deste trabalho é verificar a relação entre as determinações legais instituídas pelo Estado e o "instituinte" compreendido como a posição política da escola frente a estas determinações, o que se reflete nas propostas e nas práticas escolares. É um trabalho de cunho qualitativo que utiliza referenciais teóricos e empíricos e busca, inicialmente, compreender o que representa o Projeto pedagógico no contexto das políticas educacionais determinadas pela LDB/96 e legislação complementar, mais especificamente nas Diretrizes Curriculares Nacionais para a Educação Básica no sentido de identificar o tipo de cidadão que está sendo proposto nas políticas atuais e que relações estas têm com o modelo de Estado que as determina; num segundo momento, através de resultados de pesquisa em escolas municipais, verificar como a escola compreende as relações entre Estado e educação e como isto se reflete em seus projetos pedagógicos e nas condições de sua operacionalização. Constata-se que a escola assume novos discursos que se traduzem em projetos e propostas, reproduzindo discursos do"instituído", sem compreensão do contexto que o determina, o que impede práticas que possibilitem a recuperação do papel social da escola. Isto evidencia a necessidade de uma posição política da escola frente aos interesses sociais e aos interesses do capital, sob pena de a escola se tornar apenas um instrumento do mercado.

Palavras-chave: Estado. Políticas educacionais. Projeto pedagógico. Cidadania.

\section{State policies and school political-pedagogic organization: between instituted and instituting Abstract}

Focusing on the pedagogic project of elementary schools, this paper targets to verify the relationship between the legal decisions instituted by the State and the so called "instituting", known as the school own political position against the State decisions, which is reflected upon proposals and practices. It is a qualitative work that utilizes theoretical and empirical references that aims, initially, to understand the meaning of schools' pedagogic project in the educational policy context determined by LDB/ 96 and its complementary legislation, particularly the National Curriculum Directives for Basic Education, in order to identify the type of citizen that has been formed by the current policies and how the relation between these policies and the State that

\footnotetext{
* Doutora em Educação, Universidade Estadual de Campinas, SP; Professora da Universidade Federal de Santa Maria, RS. E-mail: sueli@ce.ufsm.br
} 
had defined them is. The next step is to verify, by using the results of a research made at municipal schools, how these organizations understand the relationship between State and education and how this relationship reflects upon schools' educational projects and their operational conditions. It can be noticed that schools assume new discourses and translate them into projects and propositions echoing "instituted" discourses, without understanding their determining context and thus blocking practices that could rescue their social role. All these things make evident how necessary it is for schools to take a political position facing social and capital interests, under penalty of becoming a mere market instrument.

Keywords: State. Education policies. Pedagogic project. Citizenship.

\section{Politicas del Estado y organización político-pedagógica de la escuela: entre el instituido $y$ el instituyente Resumen}

Teniendo como foco el proyecto-pedagógico de las escuelas, el objetivo de este trabajo es verificar la relación entre las determinaciones legales por el Estado y el "instituyente" comprendido como la posición política de la escuela frente a las determinaciones, lo que se refleja en las propuestas y las prácticas escolares. Es un trabajo de cuño cualitativo que utiliza referenciales teóricos y empíricos y busca, inicialmente, comprender lo que representa el Proyecto-pedagógico en el contexto de las políticas educacionales determinadas por la LDB/96 y legislación complementar, más específicamente en las Directrices Curriculares Nacionales para la Educación Básica en el sentido de identificar cual es el tipo de ciudadano propuesto en las políticas actuales y cuales son las relaciones de estas con el modelo de Estado que las determinan; en un segundo momento, a través de resultados de pesquisa en escuelas municipales, verificar como la escuela comprende las relaciones entre el Estado y la educación y como eso se refleja en sus proyectos-pedagógicos y en las condiciones de su operacionalización. Se nota que la escuela asume nuevos discursos que se traducen en proyectos $y$ propuestas, reproduciendo discursos del "instituido", sin la comprensión del contexto que lo determina, lo que impide prácticas que posibiliten la recuperación del papel social de la escuela. Esto reitera la necesidad de una política de la escuela frente a los intereses sociales y a los intereses del capital, para no hacer de la escuela solamente uno instrumento del mercado.

Palabras clave: Estado. Políticas educacionales. Proyecto pedagógico. Ciudadanía.

\section{Introdução}

A proposta de organização das instituições educacionais se explica pelo projeto neoliberal que, convertendo-se "no fundamento de uma nova ordem internacional, reformulada a partir das novas condições do desenvolvimento da ciência e da tecnologia" (BIANCHETTI, 1999, p. 27), estrutura as políticas de Estado e de suas instituições sociais em consonância com as exigências do mercado global, indicando que a compreensão do Estado, hoje, diz respeito a um certo grau das virtudes da descentralização 
dos processos decisórios e de sua suposta identificação com a perspectiva de construção de um sistema político-democrático, tendo seu suporte principal na nova dinâmica de organização do trabalho, pela qual se interligam o poder global e o local.

Isto explica a reestruturação mundial dos sistemas de ensino e educacionais como parte de uma ofensiva ideológica e política do capital neoliberal (HILL, 2003), do que resulta a política de descentralização de poder e, como conseqüência, institui a autonomia das instituições. Neste prisma, as mudanças estruturais no aparelho de Estado capitalista devem ser abordadas sob a ótica de uma "democracia formal" (BRUNO, 2003), determinando um modelo de organização administrativo-pedagógica que tem em práticas participativas e flexíveis a sua dinâmica, correspondendo ao que se propõe o Estado neoliberal, enquanto transfere a escola da esfera política para a esfera do mercado.

Esta lógica contaminou a Constituição Federal de 1988 (BRASIL, 1998), que tem na descentralização o princípio regulador das políticas públicas, o que é corroborado na Lei de Diretrizes e Bases da Educação Nacional - Lei n. 9.394 (BRASIL, 1996) - que, através de suas determinações, aponta para a importância da educação no conjunto dos interesses do capital, confirmando que os desafios do mundo do mercado, sob a ótica neoliberal, interferem de forma significativa e determinante nas políticas educacionais. Referenda-se, assim, a idéia de que "o motor da história encontrase nos processos produtivos" (DOWBOR, 1998, p. 19).

Valendo-se do princípio descentralizador do Estado, a escola, a menor parcela do sistema educativo, tem como desafio ocupar os espaços de autonomia legalmente instituídos, assumindo uma posição política frente aos interesses do mercado. Neste processo, a instituição educativa se organiza, ou para formar o pessoal necessário ao capital, ou, contrariamente, para formar cidadãos conscientes de seu estar no mundo, aptos a participar e contribuir para a transformação social, o que faz da posição política da escola o centro de suas propostas que se traduzem em seu projeto pedagógico.

Compreendido como o centro de definições políticas da escola, o projeto pedagógico é o resultado de decisões que envolvem a comunidade escolar como um todo no sentido de fazer da escola, não uma instituição produtora de fracassos, coadjuvante da exclusão, e sim uma instituição social promotora da humanização de seus cidadãos.

Nesta perspectiva, pensar e construir um projeto pedagógico que tenha como horizonte o resgate da função social da escola, implica uma revisão de sua organização administrativo-pedagógica, a partir do tipo de cidadão que se propõe a formar, o que exige compromisso social na redução das desigualdades entre o ponto de partida do estudante e o ponto de chegada a uma sociedade de classes.

Partindo dessas referências, este texto tem no projeto pedagógico seu foco de estudo nas relações entre o "instituído" e o "instituinte", entendendo-se com Libâneo e outros (2003), o "instituído" como as normas legais para a organização da estrutura escolar determinada pelos órgãos oficiais e vigente para a educação básica, enquanto o "instituinte" se refere à organização da escola criada pelos próprios membros da instituição no seu cotidiano. Para tanto, o presente texto busca compre- 
ender o que representa o projeto pedagógico no contexto das políticas educacionais; analisar a organização político-pedagógica determinada pela legislação educacional tendo como foco as Diretrizes Curriculares Nacionais (DCNs) para a Educação Básica que, associadas aos Parâmetros Curriculares Nacionais (PCNs), identificam o tipo de cidadão que está sendo proposto nas políticas atuais e, por fim, verificar como a escola compreende as relações destas políticas com o modelo de Estado neoliberal, o que se reflete em seus projetos pedagógicos e nas condições de sua operacionalização.

Para a efetivação deste trabalho, valemo-nos de dados coletados ao longo do desenvolvimento do projeto de pesquisa intitulado "A construção da autonomia escolar" desenvolvido na rede municipal da Região Central do Estado do Rio Grande do Sul, entre 1999 e 2003, que teve por propósito investigar a organização administrativo-pedagógica das escolas municipais e as implicações para isto: espaços democráticos de deliberações; formação continuada de professores; participação de alunos em órgãos decisórios; organização curricular; integração entre escola e comunidade; avaliação de resultados e medidas assumidas pela escola com vistas à melhoria do padrão de aprendizagem, entre outras questões que evidenciam como a escola, a partir de suas propostas e ações, ocupa os espaços de autonomia legalmente instituídos pela Lei de Diretrizes e Bases da Educação Nacional (LDB) (BRASIL, 1996).

A região em estudo, designada como Associação dos Municípios do Centro - $A$. M. Centro -, é integrada por trinta e cinco (35) municípios e, destes, dezenove (19) participaram da investigação em questão. Para tanto, foi utilizada a modalidade de pesquisa qualitativa, do tipo participante, junto ao conjunto de professores das escolas em cada uma das redes municipais envolvidas pelo projeto, o que ocorreu em reuniões com questionamentos e debates. Paralelamente, se deu a análise de documentos compreendidos em duas dimensões: a legislação educacional e os projetos pedagógicos das escolas, especialmente.

Este trabalho representa um recorte desta pesquisa e se vale dos dados da pesquisa documental compreendida, por um lado, na análise de dezenove (19) projetos pedagógicos, correspondendo ao projeto de uma escola, escolhida aleatoriamente, por município participante da pesquisa, junto ao conjunto de documentos legais que instituem as DCNs para a Educação Básica e os PCNs.

A partir desta amostra, pretende-se evidenciar, nos projetos pedagógicos, a posição assumida pelas escolas frente às atuais políticas educacionais, assim como, a tentativa de traçar algumas conclusões que relacionem a ação da escola com a realidade sociopolítica-econômica e cultural brasileira, frente ao mundo determinado pelo capital.

\section{Projeto pedagógico como compromisso social no contexto das políticas educacionais neoliberais}

Projeto pedagógico resulta da descentralização de poder instituído pelas políticas educacionais atuais e se constitui na principal responsabilidade das unidades educativas que, transformando a escola num espaço representativo 
dos interesses da coletividade, ocupe seu espaço de autonomia na busca de alternativas inovadoras, as quais a ela possibilitem oferecer uma qualidade de ensino que, não só atendam ao objetivo de formar cidadãos capazes de compreender criticamente a sociedade, aptos a assumir os desafios do mundo do trabalho, como preparados para enfrentar lucidamente o mundo competitivo e excludente em que estamos inseridos.

Este é o compromisso primeiro da comunidade educacional envolvida no processo de gestão escolar no sentido de, conscientemente, construir uma instituição que atenda às necessidades sociais, fazendo da escola um locus de formação humana para o que é preciso entender este espaço educativo no seu processo de hominização e de humanização do qual todos fazem parte e, assim, levar educando e educador a relacionarem vida e trabalho como objetos de atenção da ação pedagógica.

Estas referências conduzem a escola à realização de diagnósticos da realidade existente que indiquem caminhos para suas ações de modo a ter na aprendizagem a centralidade da ação pedagógica, indicando que o projeto pedagógico não é um plano de ensino ou um conjunto de projetos isolados, recheado de atividades diversas. Na verdade, é uma atividade política intencional quando assume, conscientemente, compromisso com a formação do cidadão para um tipo de sociedade e é pedagógico quando define ações educativas e busca alternativas necessárias para cumpri-las (VEIGA, 1995). Nesta posição, salienta Saviani (1984, p. 93), que "a dimensão política da educação se cumpre à medida em que ela se realiza enquanto prática especificamente pedagógica".

Isso implica uma organização administrativo-pedagógica da escola em que, superando a estrutura "taylorista-fordista", ainda muito presente nas organizações escolares, se construa a cultura da participação, a cultura de decisões coletivas e, neste aspecto, se faz necessária uma atualização permanente, especialmente dos professores, considerando que são eles os responsáveis primeiros pela condução deste processo.

Compreender o papel dos professores no conjunto da comunidade escolar, pressupõe uma coletividade escolar politicamente preparada para a participação, convicta de que o sucesso dos alunos está na ação dos profissionais da educação, assim como na participação dos alunos na proposta da escola, na inserção da comunidade nos assuntos da instituição e na construção de projetos que indiquem que a escola se insere num contexto mais amplo a partir de determinantes sociais, políticos e culturais, o que implica desalojar da sala de aula a idéia de exclusividade de local onde se aprende e do senso comum que permeia os conteúdos ali desenvolvidos, do que se pode dizer com Mészáros (2005, p. 9-10) que "a educação não pode ser encerrada no terreno estrito da pedagogia, mas tem de sair às ruas, para os espaços públicos e se abrir ao mundo", o que impõe mudanças na lógica racional tradicional da própria organização do conhecimento, da formulação do currículo e da modelagem única dos processos de avaliação. 
Neste quadro, o político e o pedagógico estão implícitos como dimensões essenciais do que se determina como proposta para a escola em função de sua intencionalidade e, nesta perspectiva, entende-se que o projeto pedagógico não poderá ser uma decisão individual, ou de poucos.

Como construção coletiva haverá a compreensão de que as condições de participação se enquadram nos procedimentos formais de produção e distribuição do conhecimento, dos bens culturais e do poder.

Nesta ótica, fazendo da humanização do "ser" o objetivo da ação educativa entende-se com Arroyo (1998), que a proposta da escola deverá priorizar a democratização do saber, a construção da cultura e do conhecimento no sentido de conduzir a criança, jovem ou adulto a aprender o significado social e cultural dos símbolos construídos que os cercam, o que não ocorre dissociado do mundo real, tanto da realidade social como individual das pessoas, isto porque a escola é uma instituição no conjunto das instituições sociais e, portanto, faz parte do processo de construção e reconstrução da sociedade.

Assim, "educar nada mais é do que humanizar, caminhar para a emancipação, a autonomia responsável, a subjetividade moral e ética". Compreender esse todo é a base para uma proposta pedagógica e é sobre essa "dinâmica da produção-reprodução histórica do ser humano" num processo em que, "vinculando trabalho-educação", percebe-se "o ser humano como construção histórica, o que deverá refletir-se na teoria pedagógica, ou deveria refletir" (ARROYO, 1998, p.144-145), para que a escola deve utilizar seu espaço de autonomia.

Tendo presente, no entanto, que as instituições escolares se convertem em instrumentos de ligação direta entre sistemas educativos e produtividade de mercados (SANTOMÉ, 2001), é significativo o entendimento dos limites da própria autonomia no contexto de uma sociedade de classes considerando que, no campo escolar ou escolarizado, as políticas públicas determinadas pelo projeto neoliberal não foram estabelecidas para garantir o acesso, a permanência e a qualidade da aprendizagem para as crianças e jovens de todas as classes.

Isto se compreende com Hill (2003, p. 27, grifo do autor), quando enfatiza que a escola, para o capital, através de seus profissionais, é um instrumento do sistema que deverá estar voltado para "o desenvolvimento e força da única mercadoria sobre a qual depende o sistema capitalista: a força de trabalho".

Sobre este aspecto, continua o autor (HILL, 2003, p. 27):

Os professores são os guardiões da qualidade da força de trabalho! Este potencial, este poder latente que têm os professores é a razão pela qual os representantes do Estado perdem o sono preocupando-se sobre seu papel em assegurar que os futuros trabalhadores sejam entregues aos locais de trabalho pelo capital nacional e que disponham da mais alta qualidade possível. 
Esta é uma compreensão de que deve estar consciente a comunidade escolar no sentido de definir prioridades em um projeto pedagógico que se destina à promoção humana.

A igualdade de acesso e permanência na escola, e o princípio da qualidade calcado na formação humana crítica, voltado para a transformação social são elementos primordiais a serem observados na proposta administrativo-pedagógica de uma escola democrática, e toda a ação da escola deverá estar voltada para cumpri-los.

A igualdade de acesso teve um significativo impulso, indicando ser um dos grandes feitos a partir do final do século $X X$, visto o progressivo aumento de pessoas à escolaridade básica, lembrando com Santomé (SANTOMÉ, 2001, p. 54) que:

\begin{abstract}
A longa e dura luta dos coletivos sociais mais populares pelo acesso às instituições escolares esteve sempre ligada à luta por uma sociedade mais igualitária, livre e democrática. Esquecer estas reivindicações sociais pode permitir que se voltem a gerar as condições que deram lugar à construção de sociedades injustas, autoritárias e opressoras e ao aumento de coletivos sociais excluídos.
\end{abstract}

Efetivamente, a importância que assume a Educação Básica para o capital repercute nas sociedades atuais, na oferta de educação a toda a população, o que é visível em nossa realidade pela ampliação das matrículas motivada por uma obrigatoriedade movida pelos incentivos financeiros através de fundos, especialmente para o ensino fundamental e, agora, ampliados para atingir os demais níveis da escolaridade básica. Com isto, os governos assumem compromisso com a quantidade, sem que a qualidade seja objeto da mesma importância, evidenciando que, se o acesso à escola é condição necessária, não é condição suficiente para inserir no mundo do saber e da participação consciente a maior parcela da população, cuja existência só é conhecida nos quadros estatísticos, demonstrando o fracasso da educação em nosso país.

Isto indica que o deslocamento do processo de exclusão educacional não se dá mais na questão do acesso à escola, mas dentro dela por meio das instituições de educação formal, deixando a educação à mercê dos interesses de mercado. Pode-se dizer com Mészáros (2005, p. 11-12) que "o que está em jogo não é apenas a modificação política dos processos educacionais - que praticam e agravam o apartheid social -, mas a reprodução da estrutura de valores que contribui para perpetuar uma concepção de mundo baseada na sociedade mercantil", indicando que a qualidade da educação não pode mais ser negligenciada pela comunidade escolar.

Uma escola de qualidade, voltada para os interesses sociais, é uma prerrogativa para sustentar projetos pedagógicos os quais definindo suas propostas, devem facilitar a promoção da população a níveis cada vez mais altos do sistema educativo. A idéia é construir uma instituição educativa com vistas à conquista da autonomia intelectual dos sujeitos, compreendida como a condição de alguém que se autodetermina, entendendo-se que, com a autonomia intelectual, criam-se condições para decisões participativas conscientes. 


\section{Entre o instituído e o instituinte: da legislação para a Educação Básica à organização da escola}

Governos e organismos internacionais vêm articulando discursos com ênfase na Educação Básica e na relação da educação com o conhecimento, o que se identifica nos documentos legais norteadores da organização escolar que, impostos à sociedade de cima para baixo e não com ela elaborados, se traduzem numa visão difusa para as instituições educacionais, visto a aparente identidade de propósitos da sociedade e do capital.

Neste prisma, é preciso ter clareza das políticas educacionais que, trazendo discursos inovadores, enfatizam aspectos da cultura, da formação dos domínios afetivos, além dos cognitivos, tornando-se regras para as instituições educativas e se traduzem na legislação educacional, a partir da idéia de "educação para a cidadania".

Efetivamente, "formação da cidadania" é o princípio básico da educação nos PCNs. Nesta proposta,

o global e o local justificam a importância de o sujeito tornar-se um cidadão do mundo sem que haja perda de suas raízes; considerar as características das pessoas como únicas no contexto da mundialização da cultura: o direito de escolher seu caminho e de realizar suas potencialidades na medida das possibilidades que lhe são oferecidas. Considerar a tensão entre a cultura local e a modernização dos processos produtivos de que o cidadão deverá apropriar-se, como usuário e como produtor. Para tanto, "aprender a conhecer"; "aprender a fazer"; "aprender a conviver"; "aprender a ser" são as competências necessárias ao cidadão e com elas a escolas deve-se comprometer (PARÂMETROS..., 1998, p. 15-17).

Enfim, os PCNs (PARÂMETROS..., 1998, p. 21), estabelecem que

a sociedade brasileira demanda uma educação de qualidade que garanta as aprendizagens essenciais para a formação de cidadãos autônomos, críticos, participativos, capazes de atuar com competência, dignidade e responsabilidade na sociedade em que vivem e na qual esperam ver atendidas suas necessidades individuais, sociais, políticas e econômicas.

As recomendações dos PCNs indicam uma orientação visando à superação das práticas pedagógicas existentes nas escolas por não estarem mais atendendo às necessidades apresentadas pelo atual cenário sociopolítico-econômico do país.

É possível dizer com Azanha (2001, p. 2), que a qualidade de ensino, tão apregoada pelo capital, vem sendo determinada pelos PCNs como uma nova ordenação curricular para todo o país. Através destes documentos, a idéia parece ser a de generalizar orientações curriculares condizentes com o avanço dos conhecimentos no mundo contemporâneo como condição para que as instituições educativas alcancem "padrões de qualidade" compatíveis com as exigências do capital. 
Nesta lógica, continua o autor, as diretrizes curriculares expressas pelos princípios dos PCNs, não se caracterizam por teorias científicas, mas por um conjunto de valores a serem aderidos, o que caracteriza uma nova versão do tecnicismo.

Nesta orientação se estruturam as DCNs para a Educação Básica.

As DCNs para a Educação Básica, emitidas pelo Conselho Nacional de Educação, estão explicitadas em documentos específicos para cada um dos níveis da Educação Básica: Resolução CEB nº 1/1999 (CONSELHO NACIONAL DE EDUCAÇÃ̃O, 1999), que institui as Diretrizes Curriculares Nacionais para a Educação Infantil a serem observadas na organização, articulação, desenvolvimento e avaliação de suas propostas pedagógicas; a Resolução CEB $\mathrm{n}^{\circ}$. 2/ 1998 (CONSELHO NACIONAL DE EDUCAÇÃO, 1998 a), que institui as Diretrizes Curriculares Nacionais para o Ensino Fundamental e a Resolução CEB $n^{\circ}$ 3/1998 (CONSELHO NACIONAL DE EDUCAÇÃO, 1998b), que institui as Diretrizes Curriculares Nacionais para o Ensino Médio. Nestes documentos legais, observam-se princípios comuns, entre eles, para a educação básica, calcados "na ética, na autonomia, na responsabilidade, na solidariedade, no respeito ao bem comum; nos princípios políticos dos direitos e deveres da cidadania, do exercício da criticidade e do respeito à ordem democrática; nos princípios estéticos da sensibilidade, da criatividade, da ludicidade e da diversidade de manifestações artísticas e culturais" (princípios básicos das DCNs para a Educação Básica).

Identificam-se ainda, em todos os documentos que estabelecem as Diretrizes Curriculares para a Educação Básica, idéias para uma nova escola, de modo que, através da "estética da sensibilidade, a escola substitua a repetição e a padronização pela criatividade, pelo espírito inventivo de modo a estimular a curiosidade do aluno pela descoberta do desconhecido sem, com isto, descuidar do desenvolvimento da afetividade, do reconhecimento dos direitos humanos e dos direitos e deveres de cidadania, constituindo identidades sensíveis de acolhimento da identidade do outro, da responsabilidade e do bem comum".

São princípios presentes nas DCNs para a Educação Básica (CONSELHO NACIONAL DE EDUCAÇÃO, 1998 b) como norteadores de projetos pedagógicos voltados para a formação de cidadãos

capazes de suportar a inquietação, conviver com o incerto e o imprevisível, acolher e conviver a diversidade, valorizar a qualidade, a delicadeza, a sutileza, as formas lúdicas e alegóricas de conhecer o mundo e fazer do lazer, da sexualidade e da imaginação um exercício de liberdade responsável.

Por esta Resolução, que sintetiza os princípios curriculares para a Educação Básica como um todo, o projeto pedagógico das escolas deverá contemplar:

O desenvolvimento da capacidade de aprender e continuar aprendendo, da autonomia intelectual e do pensamento crítico de modo a ser capaz de prosseguir os estudos e de adaptar-se com flexibilidade 
a novas condições de ocupação ou aperfeiçoamento; a constituição de significados socialmente construídos e reconhecidos como verdadeiros sobre o mundo físico e natural e sobre a realidade social e política do mundo em que vive; a compreensão do significado das ciências, das letras e das artes e do processo de transformação da sociedade e da cultura, em especial as do Brasil; o domínio dos princípios científicos e tecnológicos que presidem a produção moderna de bens, serviços e conhecimentos, tanto em seus produtos como em seus processos relacionando teoria e prática; a competência no uso da língua portuguesa, das línguas estrangeiras e outras linguagens contemporâneas como instrumentos de comunicação (CONSELHO NACIONAL DE EDUCAÇÃO, 1998b).

Através das propostas das DCNs se explicam os discursos oficiais e as linhas de trabalho promovidas pelos governos e pelas administrações educativas que traduzem o modelo de gestão das instituições escolares e os conteúdos e práticas que ali devem ser desenvolvidos de modo a atender às exigências dos novos modos de produção que, baseados na informática e na microeletrônica, têm na formação intelectual, a sua lógica, do que se pode dizer com Frigotto (1984, p. 151) que a escola:

[...] se insere no âmbito, não apenas ideológico do desenvolvimento de condições gerais da reprodução capitalista, mas também no das condições técnicas, administrativas, políticas que permitem ao capital "pinçar", na expressão de Gianotti, de dentro dela aqueles que, não pelas mãos, mas pela cabeça, irão cumprir as funções do capital no interior do processo produtivo.

Nesta ótica, a legislação educacional para a Educação Básica, traduzida nas Diretrizes Curriculares para a Educação Infantil, para o Ensino Fundamental e para o Ensino Médio, em acordo com os princípios da LDB (BRASIL, 1996), representa um grande desafio para o que a escola deve estar atenta aos interesses que embasam estas diretrizes, visto as aparentes coincidências de propostas entre as expectativas sociais e os interesses do capital na busca da superação do fracasso educacional.

A palavra de ordem do discurso oficial tem sido efetivamente, a melhoria da qualidade do ensino. $O$ capital reclama da escola a falta de conhecimentos e destrezas elementares, de disciplina para o cumprimento de regras prontas, da leitura e da escrita com qualidade, do que ninguém discorda. Implica, isto sim, como dizem Baudelot e Establet (1990 apud SANTOMÉ, 2001), que se busque entender "a contradição flagrante entre a elevação contínua e espetacular dos produtos da atividade humana nos mais variados campos (ciência, tecnologia, nível de vida [...])", o que corresponde a aprendizagem de habilidades e competências úteis à produção.

As reclamações dos interesses do trabalho, no entanto, esquecem como diz Santomé (2001, p. 52),

[...] de insistir, também, no desenvolvimento de destrezas, de análises, avaliação e crítica, bem como do trabalho de conteúdos cultu- 
rais com maior poder de mobilização social, de outros conteúdos que possam dotar cada cidadão e cidadã de um maior caudal de recursos para corrigir as disfunções da sociedade presente.

Continua o autor:

Num modelo de sociedade onde apenas poucas pessoas podem participar na tomada de decisões acerca dos modos de produção, distribuição e consumo, não é de esperar que o debate democrático sobre os conteúdos, as destrezas, os procedimentos, e os valores que é preciso fomentar nas novas gerações acabe por ser uma das disciplinas prementes. Normalmente será algo que se furtará à sociedade para passar a ser decidido por grupos de pessoas um tanto ocultos" (SANTOMÉ, 2001, p. 52, grifo do autor).

Neste processo estão em confronto a liberdade individual e a identidade coletiva, pelo qual, prevalece a primazia criativa do mercado como valor social representando "uma crise atual da cultura intelectual" (GÓMEZ, 2001, p. 34), o que tem afetado a educação em suas finalidades sociais.

Compreender a educação frente aos interesses do capital numa sociedade de desiguais implica a construção de um projeto pedagógico que tenha como ponto de partida a análise do contexto em termos macro e micropolítico-sociais, a partir de seus determinantes econômicos.

Nestes termos, o projeto pedagógico voltado para a formação da cidadania, só se dará, quando a escola, coletivamente e, consciente do mundo que a cerca e que a produz, tomar suas decisões. É o resultado da consciência política que deve nortear a prática da gestão democrática que tem sua base de sustentação na descentralização administrativa e na autonomia escolar.

Esta composição de forças se concretiza por decisões participativas, na qual a redistribuição de poder representa o compromisso de todos os envolvidos com a construção de uma proposta para a escola voltada para a formação da cidadania, o que implica um comprometimento de cada participante deste coletivo no sentido de efetivar uma formação para a "estética da sensibilidade que vise a transformar o trabalho repetitivo e reprodutivo em trabalho criativo" (CONSELHO NACIONAL DE EDUCAÇÃO, 1999), compreendendo, aqui, educação estética, não como tentativa isolada e romântica para enfrentar a desumanização do sistema educacional na sociedade capitalista, mas como a superação positiva da alienação, o que exige participação de professores e alunos, especialmente, em debates que permitam a ousadia de criar o novo, o inovador preparando o aluno para conviver numa sociedade instável, mas politicamente compreendida, para nela buscar alternativas próprias.

Implica a compreensão do que representa "ética, autonomia, responsabilidade, solidariedade, respeito ao bem comum (CONSELHO NACIONAL DE EDUCAÇÃO, 
1999), ou seja, afastar-se de valores instituídos na escola como verdadeiros, a partir de uma análise crítica dos mesmos, tais como o individualismo, a discriminação e a descrença na mudança.

Implica a compreensão de que o conhecimento da realidade local tem de se articular ao global e, neste particular, compreender a realidade brasileira e sua posição como país periférico, estabelecendo as prioridades para uma educação que busque superar o fracasso escolar que caracteriza a realidade da educação no Brasil. Serão conhecimentos das necessidades sociais e das prioridades do desenvolvimento humano.

ponto de partida, portanto, é o tipo de cidadão que a escola busca formar e para que sociedade. Neste contexto, é importante que a escola se posicione sobre o que entende por formação para a cidadania, tendo claro, tal como pensa Rousseau (apud FERREIRA, 1993), que a educação é um fator de cidadania. Para este pensador, educar é ajudar o indivíduo a sair de si mesmo, compreender o mundo e conviver com suas próprias limitações, buscando aperfeiçoar-se. Cidadão, portanto, é aquele que aprende a libertar-se de seus próprios limites e busca encontrar a sua plenitude na experiência política para a qual o indivíduo deverá estar sempre a serviço dos interesses da comunidade.

Na vida pública, o homem se efetiva no cidadão, reduzindo os seus interesses aos interesses da comunidade e, assim sendo, a vida humana se concentra na atividade política que, muito mais que um direito, é um dever de todos, um imperativo social. A ninguém é dado o direito de escolher se quer ou não participar. Exige-se de todos a virtude de estar sempre a serviço do bem comum.

Construir uma escola para a cidadania implica estimular a descentralização cultural provocando "o interesse intelectual inclusive por aquilo do qual discordamos" (GÓMEZ, 2001, p. 60). Exige a ruptura do egocentrismo pessoal como requisito do desenvolvimento democrático pessoal e social.

Este é um compromisso que tem sido objeto de grandes preocupações e grandes indefinições das instituições educativas, o que pode ser elucidado com a realidade evidenciada na rede de escolas municipais da região central do Estado do Rio Grande do Sul que mostra um sistema profundamente marcado pela combinação de características centralizadoras e descentralizadas em uma grande diversidade de experiências sem que maiores conceituações sobre "cidadania", "democracia", "autonomia", evidenciem clareza na compreensão das políticas educacionais e do contexto em que as mesmas se inserem.

\section{O projeto pedagógico na realidade municipal: intenções e realizações}

Compreendendo o projeto pedagógico como o resultado de decisões coletivas que identifica a escola em seus propósitos com vistas à formação para a cidadania, buscouse na realidade das escolas municipais da região central do Rio Grande do Sul verificar os avanços na construção de suas propostas, a partir de seu espaço de autonomia. 
A metodologia de trabalho valeu-se da análise de conteúdo, utilizando-se da incidência de idéias-chave evidenciadas nas propostas dos projetos analisados das instituições educativas investigadas.

São comuns nos projetos as idéias de resgatar, através da prática educativa, os valores morais, sociais e críticos da educação, respeitando-se a liberdade de expressão e o pluralismo de idéias, ou seja, educar para formar cidadãos críticos, que saibam se posicionar frente às questões do dia-a-dia, o que identifica a linguagem dos projetos com a linguagem da legislação da educação.

Na seqüência da análise dos projetos pedagógicos são comuns expressões cujo eixo principal identifica a formação do "aluno como sujeito do processo educativo"; "educar respeitando a realidade do aluno"; "respeitar os aspectos psicossocial, intelectual, motor e cognitivo"; "formar cidadãos críticos que saibam se posicionar"; "analisar a sociedade para poder contribuir na sua transformação"; "buscar a coerência entre a prática pedagógica e os aspectos afetivos dos alunos"; "ter visão do mundo de forma crítica, acompanhando as suas mudanças"; "resgatar os valores morais, sociais, críticos da educação"; "respeitar a liberdade de expressão e o pluralismo de idéias"; "basear a prática pedagógica nos princípios de solidariedade"; "construir o currículo a partir da necessidade e da realidade dos alunos", aspectos que se tornam exigência obrigatória quando se pretende uma educação para formar cidadãos comprometidos com a transformação social e não apenas preparados para "adaptar-se com flexibilidade a novas condições de ocupação ou aperfeiçoamento" (CONSELHO NACIONAL DE EDUCAÇÃO, 1998b).

Identifica-se, nas expressões destacadas dos projetos, a preocupação com a formação de um coletivo escolar de modo que este construa alternativas efetivas para o desenvolvimento de um projeto pedagógico que atenda às necessidades da formação para a cidadania: "elaborar o Plano de Estudos em conjunto com os professores de forma participativa"; "o currículo deve ser interdisciplinar e emergir de discussões conjuntas, da reflexão e da prática docente"; "avaliar de forma contínua, reveladora, com técnicas e instrumentos variados"; "avaliar respeitando a evolução do alunado"; propostas que implicam um maior aperfeiçoamento dos profissionais da educação e de avaliação permanente do processo como um todo, o que, de certa forma, está previsto nos projetos: "refletir sobre a prática docente"; "buscar um processo permanente de auto-avaliação do professor"; "incentivar e promover a busca de permanente atualização de professores".

As idéias acima, presentes nos projetos pedagógicos analisados, indicam que as instituições, apesar de preocupadas com a atualização de professores, com a formação de uma visão crítica do aluno, com a organização de trabalhos participativos, com a reflexão crítica da prática docente, com a formação de um coletivo escolar para tomadas de decisões conjuntas, entre outras, sinalizando para a necessidade de uma nova organização administrativo-pedagógica da escola, não apresentam nenhuma justificativa para tais propostas, assim como não apresentam nenhuma meta ou proposição de alteração da estrutura das instituições que venham a favorecer a operacionalização destas propostas. 
Esta constatação sinaliza para um distanciamento entre o discurso e a prática, o que reflete a posição política assumida pela escola, visto que é na ação que as políticas se consolidam. Se este é o fator que revela o "instituinte", evidencia-se que a escola ainda não ultrapassou o senso comum que tem determinado a organização escolar e ainda se ressente de uma análise consistente de sua própria realidade e de seu contexto. Em outras palavras, a escola, a partir de seus profissionais, se isenta de uma compreensão crítica do modelo de Estado e de seus propósitos, assim como, internamente, de uma avaliação da escola existente, de seus avanços e descontinuidades, do que se propõe e do que realmente faz em busca da formação de cidadãos capazes de enfrentar o mundo do trabalho e de criar condições de superação dos problemas do cotidiano, o que indica a exigência de revisão dos valores em que a escola está assentada.

Nesta perspectiva, seguindo as orientações legais, a escola busca integrar-se em uma nova proposta sem, no entanto, subsidiar-se de uma compreensão da totalidade social e de suas contradições e, neste processo, valendo-se do princípio descentralizador do Estado, prevalecem os interesses do capital de modo que, incentivando a autonomia das instituições, as deixa à mercê de suas próprias possibilidades numa lógica em que o individualismo, como parte integrante da ideologia liberal, responsabiliza cada escola por seu fracasso ou sucesso.

As poucas idéias que sinalizam para a possibilidade de análise de contexto nos projetos pretendem "promover condições para que o aluno acompanhe progressivamente as mudanças do mundo, que possa ter visão do todo, nestes tempos de globalização, de forma crítica". Neste particular, novamente, não se observa maior fundamentação sobre o assunto, assim como nenhuma proposta curricular condizente com o propósito é apresentada, o que indica que as instituições educativas se têm utilizado de um discurso pronto, instituído pela legislação educacional, sem que haja uma real tomada de consciência do que o mesmo representa para uma mudança substantiva das práticas escolares no contexto em que se inserem, confirmando que a escola está "em descompasso entre suas propostas e suas práticas" (PARO, 2001, p. 29). Nessas condições, corre-se o risco, como salienta Azanha (2001), "de que se faça uma reforma de uma realidade educacional da qual temos apenas uma visão em grande parte impressionista".

Esta é uma problemática de fundamental importância, na qual se torna imprescindível a formação continuada de professores no sentido de sua conscientização e politização na perspectiva de superação da condição que têm assumido como meros "decodificadores de pacotes de saber produzidos em série" (FRIGOTTO, 1984, p. 99), prática dissociada de qualquer compreensão mais ampla das políticas educacionais no contexto neoliberal que as determina.

Apesar de os projetos apresentarem a proposta de "incentivar e promover a busca de permanente atualização de professores", a contradição entre o discurso e a prática inviabiliza o determinante princípio relacionado com a formação inicial e continuada de seus profissionais, isto porque a mudança "é aquela que contempla a figura do educador, esteja ele na função que estiver. [...] se ele não se dispuser a reconstruir sua formação e autogerir o aprimoramento profissional, todo processo estará comprometido" (RESENDE, 1995, p. 90). 
Superar estas limitações compreendendo criticamente o "instituído" no contexto da sociedade neoliberal que o determina e fazer dele um "instituinte" relevante para a escola numa tentativa de recuperar seu papel social, não significa conhecer a realidade social para prever e controlar, mas para compreender os fenômenos e os que deles participam de modo a tornar as ações da escola mais ricas e reflexivas. $O$ objetivo não é a produção de leis ou generalizações independentes do contexto, mas a compreensão dos significados do próprio contexto.

As limitações constatadas entre as propostas e as possibilidades de uma prática coerente mostram que o processo de expansão da escola se deu sem o acompanhamento de uma distribuição eficiente dos serviços oferecidos. Referenda-se, assim, a crise de qualidade que atinge a escola, o que reflete a sua ineficácia e a incompetência dos que nela trabalham.

Para Gentili (1998, p. 22):

A escola funciona mal porque as pessoas não reconhecem o valor do conhecimento e investem pouco em seu "capital humano"; os professores trabalham mal e não se atualizam; os alunos fazem de conta que estudam, quando, em realidade, perdem tempo, etc. A sociedade não apenas sofre a crise da educação. Ela também a produz e a reproduz.

O autor analisa a inoperância da comunidade escolar à medida que esta não adquire a consciência crítica de seu papel na sociedade, deixando-se privatizar pelo prejuízo imposto a muitos e pelos privilégios que beneficiam alguns através do sistema educacional, reproduzindo a sociedade de classes e fazendo com que o discurso neoliberal de que o Estado é ineficaz para gerir bem as organizações públicas, acabe por empurrar a educação para as leis do mercado, pelo qual a educação passou a ser concebida como sendo dotada de valor econômico próprio, ou seja, valorização da educação básica geral para formar mão- de- obra com capacidade de abstração, polivalente, operários flexíveis e criativos, reféns da segmentação e da exclusão.

A falta de discussões coletivas sobre estes aspectos de crucial importância para as decisões de um projeto pedagógico, tornam o "instituinte" sem possibilidades de operacionalização, pois, mesmo pretendendo "formar cidadãos críticos que saibam se posicionar", "proporcionar um currículo interdisciplinar a partir de discussões conjuntas", "construir o currículo a partir da necessidade e da realidade dos alunos" - propostas comuns apresentadas nos projetos analisados - são situações que implicam, necessariamente, a presença de professores preparados política e tecnicamente para a condução do processo.

Por sua vez, a tradição da dependência de decisões de órgãos acima da escola ainda não foi abandonada, visto que é comum nos projetos analisados a idéia de "elaborar o Plano de Estudos com o auxílio da Secretaria Municipal de Educação - SMEd -, de acordo com a legislação", evidenciando que a falta de informações implica decisões que deverão ser acatadas pela comunidade e não decididas com ela, pois ninguém decide conscientemente sem uma base sólida de conhecimento da questão em estudo. 
Por sua vez, a organização administrativo-pedagógica não é questionada nos projetos, o que mostra a presença da cultura de decisões centralizadas numa estrutura individualista, setorizada e hierarquizada, o que impede mudanças substanciais na instituição educativa.

Não se altera uma estrutura pedagógica sem alterar, coerentemente, a estrutura organizacional de modo que a visão de globalidade supere a visão parcelada e a divisão social do trabalho, do que se pode dizer com Santomé (2001, p. 54) que "nada (é) mais perigoso que submeter as instituições escolares à ditadura das teorias econômicas e empresariais", fator impeditivo de decisões democráticas, fazendo com que os princípios norteadores da igualdade, da qualidade e da diversidade se tornem um discurso vazio e sem eco na instituição educativa.

Uma organização para a mudança tem, necessariamente, como ponto de partida uma análise da realidade existente, o que implica compreensão crítica da própria realidade. Isto pressupõe encontros com a comunidade para decisões coletivas, sem o que é inviável uma prática condizente com a idéia de democracia participativa e, neste caso, o fundamento da organização democrática "se converte num puro e falso artifício se os indivíduos não têm possibilidades reais de participação, ou se as diferenças individuais se convertem em desigualdades ou discriminação" (GÓMEZ, 2001, p. 60).

Se entendermos que as condições de participação se enquadram nos procedimentos formais concretos de produção e distribuição do conhecimento, dos bens culturais e do poder, a falta de construção de espaços participativos demonstra a permanência da cultura do individualismo e do centralismo, evidenciando que a escola não está suficientemente preparada para assumir a sua autonomia, não está pronta para assumir compromisso com a liberdade considerando que "autonomia e liberdade fazem parte da própria natureza do ato pedagógico" (VEIGA, 1995, p. 18-19).

Partindo desta realidade, vemos o triunfo dos interesses do capital em manter a escola como um instrumento de sua legitimação, pois, apostando no despreparo das instituições educativas, se vale do "instituído" para assumir os espaços de autonomia da escola. Desta forma, a escola, apenas cumprindo tarefas e reproduzindo discursos, fica impossibilitada de formar cidadãos "capazes de suportar a inquietação, conviver com o incerto e o imprevisível, acolher a diversidade, valorizar a qualidade" (CONSELHO NACIONAL DE EDUCAÇÃO, 1998b), de forma crítica e contextualizada, o que faz da escola uma instituição cúmplice das contradições do sistema.

Nesta ótica, o conjunto de princípios explícitos nas DCNs para a Educação Básica, reforçadas pelas normativas práticas colocadas pelos $\mathrm{PCN}$ fazem com que a escola, através de seus profissionais, estimulem o educando a assumir solitariamente as incertezas da vida e a enfrentar o provisório, respondendo apenas ao imediatismo de suas necessidades, flexíveis para o trabalho e para o consumo, retirando dele a possibilidade de apropriar-se dos bens sociais já realizados e disponíveis na sociedade.

A escola tem de ter presente que os fatos que ocorrem na realidade são profundamente dinâmicos, trazendo novos desafios para a educação, exigindo discussões conjuntas para superar o conservador, buscando alternativas de um projeto que 
responda aos anseios da sociedade e não apenas reprodução de propostas, planos ou diretrizes com discursos voltados para uma ordem democrática e progressista, mas, na verdade, reprodutores de ações antidemocráticas com conteúdos sem significado para os alunos e reforçadores de estruturas repressoras e excludentes.

Esta realidade amplia o compromisso da escola em analisar criticamente os antagonismos que permeiam uma sociedade capitalista e, ao mesmo tempo, crescer na direção das necessidades da maioria da população não recusando qualquer tipo de abertura, como diz Resende (1995), mas fazer uso dela sem ter conhecimento do processo no qual está inserida é caminhar ingenuamente, como se a sociedade capitalista não contivesse em seu interior interesses antagônicos.

Reconhecer as contradições sociais, indica a necessidade da escola ser um espaço aberto, plural, crítico. Não pode ser um espaço fechado e ingênuo, ou como diz Resende (1995, p. 57), "um espaço de mediocridade, (calcado) em valores como o individualismo, a neutralidade, a competição, intensificados pela estrutura capitalista da organização social".

Não são, portanto, propostas recheadas de discursos inovadores a essência de projetos-pedagógicos para a efetiva transformação da escola. Deve ter uma comunidade escolar atenta aos seus propósitos, lúcida de que "o desafio que representa o projeto pedagógico traz em si a exigência de entender e considerar o projeto como um processo sempre em construção, cujos resultados são gradativos e imediatos" (BUSSMANN, 1995, p. 38), o que indica a necessidade de acompanhamento permanente dos resultados, habilidade que a escola deve aprender num esforço comum e responsável, no sentido de não perder de vista o tipo de cidadão que se propõe a formar.

\section{Considerações finais}

O princípio descentralizador do Estado vem evidenciando uma redistribuição de poder entre instâncias governamentais, entre poderes estatais e entre o Estado e a sociedade - redistribuição de competências, de recursos, de encargos originários dos organismos centrais, o que implica uma redivisão do trabalho entre diferentes instâncias do sistema.

Compreendendo a descentralização como uma política instrumental e não como um fim em si mesma, o êxito deste processo só é avaliável através de seus resultados no confronto com os objetivos propostos.

Neste particular se identifica o direcionamento das DCNs para a Educação Básica que, inseridas nas determinações do capital, visam à formação da força de trabaIho com nível mais alto de conhecimentos, recursos humanos flexíveis e adaptáveis para o atendimento dos novos modos de produção de base científica e tecnológica.

Cumprindo determinações legais, a escola aproxima seu discurso dos ditames do capital que oferece elementos para a mudança, o que não nega os interesses de uma políitica global de mercado, visto que a provisoriedade e a flexibilidade para mudan- 
ças é o que vem sendo requerido à escola, no sentido de se adaptar aos interesses da produção, através da formação da força produtiva. Referenda-se, assim, a idéia de que a organização curricular orienta a formação de sujeitos que respeitem o pluralismo, sejam tolerantes, solidários e flexíveis à mudança, o que se configura como uma forma pacífica na solução de conflitos que venham a desestabilizar o sistema.

A escola, assim, se afirma como instrumento dos interesses das relações de produção preparando melhor o homem para "suportar a inquietação, conviver com o incerto e o imprevisível, acolher a diversidade, valorizar a qualidade, a delicadeza, a sutileza" (CONSELHO NACIONAL DE EDUCAÇÃO, 1998b), o que se caracteriza como uma formação de aspectos atitudinais e comportamentais. Essa é a dimensão proposta nas DCNs que, reforçada pelos PCNs, compreendidos pela escola como regra, tornam a escola o locus de formação de competências para o "aprender a aprender" e para a submissão, o que torna sem sentido qualquer compromisso ou prática voltada para a transmissão de conhecimentos científicos construídos historicamente, assim como distancia a escola de qualquer compromisso com a compreensão crítica da realidade social, política e econômica que determina nossa vida.

Nesta perspectiva, as DCNs traduzidas nos documentos legais, representam instrumentos impeditivos, tanto da autonomia profissional dos docentes, como da autonomia pedagógica das escolas com seus reflexos na organização escolar como um todo.

Isto se retrata em suas propostas e práticas que, associadas à democratização da gestão, compreendida e interpretada como reunião de pessoas para decidir o decidido, possibilitam entender que a democracia política formal determinada pelo mundo do mercado e que se reproduz na organização das instituições sociais "constitui-se a base dos novos modelos organizacionais [...], de decisões circunscritas ao nível técnico-operacional e, na autonomia controlada", aos moldes do que as empresas outorgam aos trabalhadores (BRUNO, 2003, p. 40), isto porque, no neoliberalismo, a democracia deixa de existir, quando os interesses da minoria submetem a maioria.

Neste cenário, limitada pela participação regrada, a comunidade escolar aceita passivamente as mudanças sendo convidada a opinar e aprovar as políticas determinadas pelo capital no campo educacional (GENTILI, 1998).

A reversão deste processo implica consciência política e visão crítica do contexto neoliberal que determina as organizações sociais. Esta é uma prerrogativa para a escola na condução da construção do projeto pedagógico que, não só representa um compromisso coletivo com a definição do que propõe como finalidade social para a instituição educativa, como representa um espaço de luta pela formação da cidadania comprometida com a transformação social.

Por sua vez, a construção coletiva do projeto pedagógico, também representa um espaço importante na superação da divisão do trabalho, enquanto fator de redução das hierarquias e construção da democratização da gestão escolar.

É significativa uma nova organização administrativo-pedagógica da escola que esteja comprometida com a compreensão crítica de realidade e, de forma interdisciplinar e contex- 
tualizada, seja planejada e executada. Esta é uma exigência da escola de qualidade que se pretende alicerçada em "princípios éticos, estéticos e políticos", pelos quais, as práticas pedagógicas se alteram no sentido de "substituir a repetição e a padronização, estimulando a criatividade, o espírito inventivo, a curiosidade pelo inusitado e a afetividade" (CONSELHO NACIONAL DE EDUCAÇÃO, 1998b), sem descuidar da visão política do aluno.

Esta conquista ainda não é a tônica dos projetos pedagógicos das escolas municipais da região central do RS, visto o descompasso entre suas ações e suas propostas que, identificando seu discurso com as determinações legais, assumem uma postura mais cumpridora de normas prontas, do que de busca de reais mudanças na organização administrativo-pedagógica, indicando a necessidade em reconhecer que as escolas não podem continuar trabalhando dentro de um único marco cultural, especialmente o que se traduz na linguagem do capital, o que tem feito com que as organizações escolares ainda se encontrem numa perspectiva "taylorizada", setorizada e, conseqüentemente, com uma organização curricular parcelada limitando a visão do aluno sem que este compreenda e se compreenda em seu contexto. Estas situações tornam o projeto pedagógico, não uma proposta efetiva de resgate da função social da escola, e sim, mais uma burocracia sem condições de operacionalização, dissociado de qualquer possibilidade de formação para a cidadania.

Assim, se conservam as estruturas existentes, a sistemática de costumes, de privilégios, de concentração de poder, de estímulo à dependência e à passividade.

Ponto de partida para a construção de uma nova organização administrativopedagógica para a escola está em compreender a realidade existente partindo do entendimento das causas do fracasso do sistema educativo e da incerteza de seus agentes. É preciso entender a escola como um lugar de construção, como um espaço permanentemente aberto e inacabado ao desenvolvimento individual e social e isto será sempre resultado de uma tarefa coletiva.

É importante lembrar com Gómez (2001, p. 46) que

[...] os docentes e a própria instituição escolar se encontram diante do desafio de construir outro marco intercultural mais amplo, mais flexível que permita a integração de valores, idéias, tradições, costumes e aspirações que assumam a diversidade, a pluralidade, a reflexão crítica e a tolerância tanto como a exigência de elaborar a própria identidade individual e grupal.

A tarefa coletiva, envolvendo a comunidade escolar como um todo (pais, alunos e, principalmente professores), representa uma ética de procedimentos democráticos que não mostra um caminho único a seguir, mas, "um procedimento repleto de pressupostos que devem garantir a igualdade na comunicação e a imparcialidade do próprio procedimento" (GÓMEZ, 2001, p. 52). Neste caso, o consenso democrático não implica um acordo, nem em posições uniformes sobre os problemas que afrontam a sociedade e a escola. Implica isto sim, um acordo sobre o marco em que se movem as variadas posições, ou o dissenso e, neste processo, a escola não se deve 
furtar de estabelecer criticamente as relações entre educação e o mundo do trabalho que permeiam as políticas educacionais como fundamento para uma tomada de posição que a ela garanta maior sucesso na nova caminhada.

No dizer de Santomé (2001, p. 58):

Preparar uma comunidade com capacidades, destrezas, valores e conhecimentos para levar a cabo esta tarefa, obriga aqueles que têm responsabilidades no sistema educativo a olhar muito além das necessidades (do mercado). [...] não é fácil que uma pessoa pense que a única coisa que deve proporcionar-lhe o sistema escolar são conteúdos para desempenhar um determinado posto de trabalho [...] e que, ao mesmo tempo, se sinta motivada pelo conhecimento da história, da literatura, que perceba a necessidade de desenvolver capacidades para analisar criticamente discursos, para julgar realizações humanas em função de interesses comunitários, que procure dos seus professores tarefas escolares com o fim de conseguir o desenvolvimento de uma maior sensibilidade artística, que valorize as suas aprendizagens na medida que a ajudam a um maior compromisso com os direitos humanos, com a defesa da liberdade, que esteja disposta a ser julgada em relação às suas condutas [...].

É um direito de o cidadão compreender o mundo competitivo e excludente em que vive, um mundo em que se reduzem, a cada dia, as possibilidades de participar democraticamente na definição do tipo de sociedade que beneficie a todos. Compreender esta realidade é um ponto necessário para a transformação social "na qual a igualdade de oportunidades seja real e não um mero slogan que serve para ocultar um mundo não solidário e injusto, um mundo em que as cartas estão distribuídas de modo muito desigual" (SANTOMÉ, 2001, p. 58).

Naturalmente que esta não é uma luta de sujeitos isolados e, neste processo de compreensão crítica do contexto, democratizam-se as relações na escola entendendo que:

a democracia é um esquema formal em permanente construção de procedimentos para enfrentar, mediante o diálogo, a informação compartilhada, o debate e a decisão majoritária, os inevitáveis conflitos, desacordos e discrepâncias que aparecem na organização [...], o que exige mais relaxamento no coletivo e maior maturidade responsável no pessoal do que nenhum outro sistema político (GÓMEZ, 2001 , p. 58).

A compreensão crítica destes pressupostos são requisitos para a construção de projeto pedagógico numa perspectiva humanizadora.

Sem esta consciência, a reforma estrutural do sistema educacional, pilar ideológico do neoliberalismo, indicada pelos processos de descentralização e autonomia, coloca para a escola, através de discursos inovadores para a sua organização administrativo-pedagógica que se configuram nas Diretrizes Curriculares, o papel de prover a ideologia de mercado e, assim, cúmplice do sistema, torna-se uma instituição produtora de fracassos, enquanto instrumento de conformação dos sujeitos com as estruturas excludentes do capital. 


\section{Referências}

ARROYO, M. Trabalho-educação e teoria pedagógica. In: FRIGOTTO, G. (Org.). Educação e crise do trabalho: perspectivas de final de século. 2. ed. Petrópolis: Vozes, 1998.

AZANHA, J. M. P. Parâmetros Curriculares Nacionais e autonomia da escola. International Studies on Law and Education, v. 3, 2001. Disponível em: <http:// www.hottopos.com/harvard3/zemar.htm>. Acesso em: 29 jul. 2008.

BIACHETTI, R. G. Modelo neoliberal e políticas educacionais. 2. ed. São Paulo: Cortez Editora, 1999.

BRASIL. Constituição (1988). Constituição da República Federativa do Brasil. 2. ed. São Paulo: Oliveira Mendes, 1998.

. Lei $\mathrm{n}^{\circ}$. 9.394, de 20 de dezembro de 1996. Estabelece as diretrizes e bases da educação nacional. Brasília, DF, 23 dez. 1996. Disponível em: <http:// www.planalto.gov.br/CCIVIL_03/LEIS/L9394.htm>. Acesso em: 29 jul. 2008.

BRUNO, L. Reestruturação capitalista e Estado Nacional. In: OLIVEIRA, D. A.; DUARTE, M. R. T. Política e trabalho na escola: administração dos sistemas públicos de educação básica. Belo Horizonte: Autêntica, 2003.

BUSSMANN, A. O projeto político-pedagógico e a gestão da escola. In VEIGA, I. P. A. (Org). Projeto Político Pedagógico da Escola: uma construção possível. 12. ed. Campinas: Papirus, 1995.

CONSELHO NACIONAL DE EDUCAÇÃO. Câmara de Educação Básica. Resolução CEB n. 1, de 7 de abril de 1999. Institui as diretrizes curriculares nacionais para a educação infantil. Diário Oficial [da República Federativa do Brasil], Brasília, DF, 13 abr. 1999. Seção 1, p. 18. Disponível em: <http:// portal.mec.gov.br/cne/arquivos/pdf/CEB0199.pdf>. Acesso em: 29 jul. 2008.

Resolução CEB n². 2, de 7 de abril de 1998. Institui as diretrizes curriculares nacionais para o ensino fundamental. Diário Oficial [da República Federativa do Brasil], Brasília, DF, 15 abr. 1998. Seção 1, p. 31 . Disponível em: <http://portal.mec.gov.br/cne/arquivos/pdf/rceb02_98.pdf>. Acesso em: 29 jul. 2008.

Resolução CEB n. 3, de 26 de junho de 1998. Institui as diretrizes curriculares nacionais para o ensino médio. Diário Oficial [da República Federativa do Brasil], Brasília, DF, 5 ago. 1998. Seção 1, p. 21. Disponível em: <http:// portal.mec.gov.br/cne/arquivos/pdf/rceb03_98.pdf>. Acesso em: 29 jul. 2008.

DOWBOR, L. A reprodução social: proposta para uma gestão descentralizada. 2. ed. Petrópolis: Vozes, 1998. 
FERREIRA, N. T. Cidadania: uma questão para a educação. Rio de Janeiro: Nova Fronteira, 1993.

FRIGOTTO, G. A produtividade da escola improdutiva. São Paulo: Cortez: Autores Associados, 1984.

GENTILI, P. A falsificação do consenso: simulacro e imposição na reforma educacional do liberalismo. Petrópolis, RJ: Vozes, 1998.

GÓMEZ, A. I. P. A cultura escolar na sociedade neoliberal. Porto Alegre: ARTMED, 2001.

HILL, D. O neoliberalismo global, a resistência e a deformação da educação. Currículo sem Fronteiras, v. 3, n. 2. p. 24-59, jul./dez. 2003. Disponível em: <http://www.curriculosemfronteiras.org >. Acesso em: 29 jul. 2008.

LIBÂNEO, J. C.; OLIVEIRA, J. F.; TOSCHI, M. S. Educação escolar: políticas, estrutura e organização. São Paulo: Cortez, 2003.

MÉSZÁROS, I. A educação para além do capital. São Paulo: Boitempo, 2005.

PARÂMETROS Curriculares Nacionais: terceiro e quarto ciclo do ensino fundamental: introdução aos parâmetros curriculares nacionais. Brasília, DF: Secretaria de Educação Fundamental, 1998.

PARO, V. H. Políticas educacionais: considerações sobre o discurso genérico e a abstração da realidade. In: DOURADO, L. F.; PARO, V. H. (Org.). Políiticas públicas e educação básica. São Paulo: Xamã, 2001.

RESENDE, L. M. G. Paradigma - relações de poder - Projeto Político Pedagógico: dimensões indissociáveis do fazer educativo. In: VEIGA, I. P. A. (Org.). Projeto Político Pedagógico da Escola: uma construção possível. 12. ed. Campinas: Papirus, 1995.

SANTOMÉ, J. T. A construção da escola pública como instituição democrática: poder e participação da comunidade. Currículo sem Fronteiras, v. 1, n. 1.p. 5088. jan./jun. 2001. Disponível em: <http://www.curriculosemfronteiras.org>. Acesso em: 29 jul. 2008.

SAVIANI, D. Escola e democracia. São Paulo: Cortez: Autores Associados, 1984.

VEIGA, I. P. A. Projeto Político Pedagógico da escola: uma construção coletiva. In: VEIGA, I. P. A. (Org.). Projeto Político Pedagógico da Escola: uma construção possível. 12. ed. Campinas: Papirus, 1995.

Recebido em: 14/02/2007

Aceito para publicação em: $17 / 12 / 2007$ 